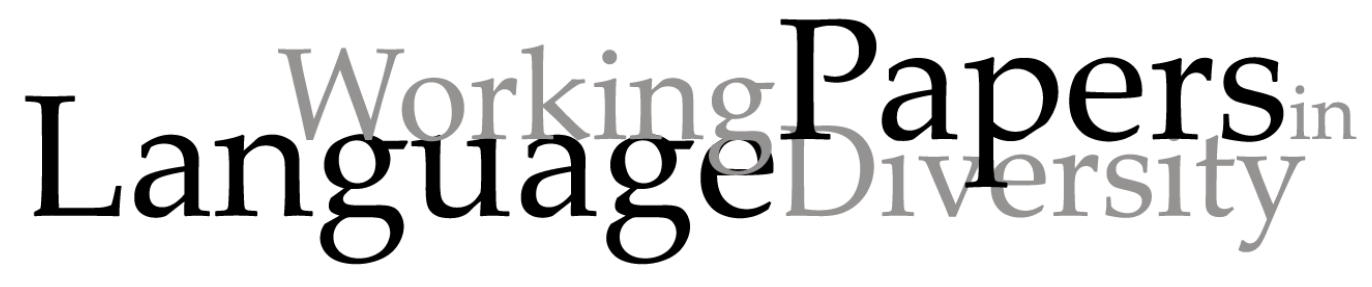

Paper 4 .

\title{
“Isn't it enough to be a Chinese speaker": Language Ideology and Migrant Identity Construction in a Public Primary School in Beijing
}

Jie Kathy Dong

University of East London

Submitted to: Language \& Communication

Contact: jie_dong77@yahoo.co.uk

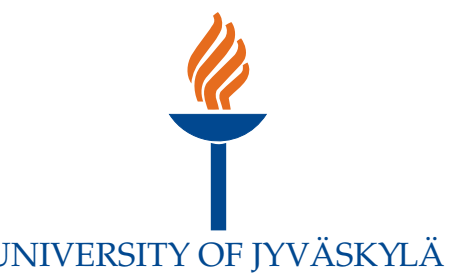




\begin{abstract}
This article explores the establishment of migrant identities through linguistic and sociolinguistic exchanges in a public school in Beijing. On the basis of ethnographic observation and metapragmatic discourses, the research demonstrates how the microscopic linguistic differences of migrant children index the cultural and metapragmatic factors at a linguisticideological level, and how such differences serve as a ground for the dialogical process of identity construction. Three vignettes illustrate this process. The first one presents a class observation in which a migrant pupil articulates a discourse on her own and her fellow-pupil's identities. It demonstrates awareness of her rural and migrant identities and of the negative indexical values such identities project. The migrant pupil overlays this migrant identity with a stable category of national identity through a claimed belonging to a homogeneous language community. The blur of migrant and local identities, however, is challenged in the interviews with a local Beijing pupil and a local teacher in the second and the third examples. The second example shows the comments of a local Beijing pupil on his migrant fellow-pupil's accent which marks as being of rural origin, a migrant to the city, unsophisticated and less intelligent; and the third example examines a teacher's comments on her pupil's identity, language, and how such identities have an impact on the pupil's appraisal. The research suggests that small features of language become emblematic of individual and group identities, and such identities can be an impact on the appraisal of migrant pupils' performance at school as well as in frames of a macro-political order invoking homogeneism within the dominant language ideologies in education, emphasising linguistic uniformity and homogeneity.
\end{abstract}

Key words: migration, identity, speech community, indexicality, language ideology, China 


\section{Introduction}

Schools, and the educational system in general, are among the key institutions that embody dominant social values and reproduce social hierarchies in a seemingly neutral form. In schools pupils from various social and linguistic backgrounds enter into interaction with one another and with educational practitioners on a daily basis. The microscopic linguistic differences that occur in such interactions often index cultural and metapragmatic factors at a language-ideological level and serve as a ground for the dialogical process of identity construction among pupils. As in many parts of the world, diversity is an increasingly salient feature of China's linguistic and sociolinguistic landscape, particularly as the mass internal migration results in rapid linguistic exchanges among members of different communities.

Since the early 1980s rural Chinese have relocated to the urban areas in search of jobs and of better life opportunities and the past two decades have witnessed an intense internal migration in scale as well as speed. It is facilitated by the rapid economic and social changes both from inside China, and with China's participation in globalisation. Urban public schools that used to mainly admit local children are now populated with both local and migrant children who bring in different social, linguistic and cultural backgrounds. When 'big' identity features such as nationality and ethnicity are shared, often as a result of political or ideological principles, 'small' differences such as accents and dialects become salient features that allow peers and teachers to differentiate between 'us' and 'them' (Blommaert, Creve \& Willaert 2006).

Difference is often converted into inequality, which in turn leaves marks on migrant children's identity as well as on their opportunities in life (Dong \& Blommaert 2007).

To explain how linguistic features function as identity markers in a Beijing public school, this paper draws upon the concepts of indexicality, ethnolinguistic identity, and speech community, and posits the arguments in the theoretical frame of language ideology (Gumperz 1968; Silverstein 1996, 1998; Rampton 1998; Blommaert 2005, 2006). On the basis of ethnographic observation and metapragmatic interviews, I will demonstrate how small features of language become emblematic of individual and group identities, and how such identities have an impact on the appraisal of migrant pupils' performance at school as well as in wider frames of macro-political order which often invoke homogeneism within the dominant language ideologies in education, emphasising linguistic uniformity and homogeneity. (Blommaert \& Verschueren 1998).

In what follows, first I shall introduce the key theoretical notions and contextualise the notions against the linguistic and social backgrounds of China; secondly, empirical data collected and analysed between March and August 2007 in Beijing will be presented as an 
illustration of the dialogical practice of migrant identity construction through metapragmatic discourses of Beijing local pupils, local teachers, as well as migrant pupils themselves. In the final section, I shall summarise the research and reflect on the theoretical discussions at a language ideology level demonstrated in the observation.

\section{Key concepts in the China context}

The notion of speech community has an intellectual history of more than a century. It runs from Herder's assumption on the automatic relations between language and community (i.e. a people, nation, ethnic group), to Saussure's collective 'mass of speakers' (Saussure 1966/1916), and Bloomfield's frequency of communication - a behaviourist definition of speech community (Bloomfield 1933). The linguistic anthropological approaches have increasingly provided arguments for revising the definition of speech community. In this current of changes, John Gumperz' fieldwork in a North Indian village and a Northern Norwegian town demonstrates that the quality of interaction is equally important than the density of contact, if not more, in language convergence and differentiation; and speech community is defined by Gumperz as 'a field of action where the distribution of linguistic variants is a reflection of social facts. This definition emphasises multilingualism and linguistic repertoires rather than presumed uniformity (Gumperz 1968:383; Gumperz and Hymes 1972; Gumperz 2003).

The rise of language ideology as a separate field of enquiry in linguistic anthropology facilitates the understanding of speech community by drawing in key insights from the socialscientific study of ideology. In a language ideology approach, Michael Silverstein (1998) distinguishes speech communities from language communities, arguing that language communities are ideological constructs; it entails people's allegiance to a shared denotational code of language known by names (e.g. English, French, Chinese); by contrast, speech communities are practical constructs, comprised of speakers that display joint orientations towards 'presupposable regularities' and such sharedness of indexical values can result in the construction of identities and communities (Silverstein 1998; see also Blommaert 2006).

Therefore language community is a specific kind of speech community, in which people display a shared orientation toward the presupposition of normative usage and result in ethnolinguistic identity associated with the denotational code, e.g. I am a native speaker of Chinese, or I speak Mandarin.

Ethnolinguistic identities such as 'I am a native speaker of Chinese' are often taken for granted, but when we look into the so called 'Chinese language' closely, things become more complex on the ground. Linguistic diversity, rather than uniformity, is the rule in China, a nation 
hosting at least 56 officially categorised ethnic groups. Many groups traditionally speak their own languages, such as Mongolian and Korean, and the name 'Chinese' (Zhongwen or Hanyu) only refers to the language spoken by the majority Han Chinese. But even this term is too singular to define the language because of the many varieties it represents. Linguists often categorise the varieties into seven major dialects: Gan, Guan (Mandarin), Kejia (Hakka), Min (including the Hokkien and Taiwanese variants), Wu (including Shanghainese), Xiang and Yue (Cantonese). This generalising approach has its defects, however; it notably overlooks intralinguistic differences. Thus one may find it difficult to count the varieties within Min dialect, for example, as once a Min speaker confessed to me that the local vernacular varied so greatly that she could not understand people of another village ten kilometres away from her own.

In the actual practice of social life, people link language varieties with particular places, e.g. Dongbei dialect (the dialect of the north-east region), Henan dialect (the dialect of Henan province). This usage is also problematic, as an informant whose place of origin was Henan province pointed out that his own accent was closer to that of his Anhui classmate than the Henan ones, because his home village was near to the borders of Anhui province. Therefore we can see here that language community is an ideological construct based on imagined linguistic boundaries, and the practical alignment in communicative activities has little to do with language names. The group identity constructed through such communicative activities is not as homogeneous and static as ethnolinguistic identities would suggest: the Henan informant is a speaker of Henan dialect by the definition of ethnolinguistic identity, and he believes that he is a native speaker of Henan dialect, but the actual identities articulated by his linguistic practice are multiple - talking in Henan dialect with those who were from the same province would project a provincial identity; using his particular variety of 'Henan' dialect with his friend, the Anhui classmate, would orientate himself towards shared indexical values of that specific locality; the Henan informant told me the story in Putonghua (literally 'common language') which entated his identity - being well-educated and of high social mobility. As speech communities are unstable and multiply, so are identities.

In the linguistically complex land that China is, Putonghua represents yet another layer to this complexity. It is a standardised variety of Mandarin spoken in Beijing and its nearby regions. People acquire Putonghua through formal education, as it is institutionally supported as the language of instruction in schools, as well as the official language in the state's other institutions. Being a language for public life, Putonghua is translocal and affords social and geographic mobility, whereas dialects are local and for private occasions. The ideology of homogeneity and uniformity is centred on the use of Putonghua and thus often overlays the 
actual diversity - Putonghua and dialects can be seen as an agglomerate of different varieties that operate and can be deployed as a repertoire (Silverstein 1996; Dong \& Blommaert 2007). In this polyglot repertoire the varieties are not equal; some of them are ranked higher than others, in relation to the orders of indexicality they orientate to (Blommaert 2002). An extract from my fieldnotes may illustrate this well:

\section{Extract 1}

I had a chat with my friend Xiao Li this afternoon. She complained that her boyfriend Xiao Liu asked her to look for a job for his brother who came to Beijing from their hometown a while ago. When she talked to Xiao Liu's brother, she couldn't even understand a word he spoke - "what kind of education did he have if he couldn't even speak Putonghua?" she commented [Fieldnotes 2007-01-26-02].

In the extract, Xiao Li was a local Beijing person who had a higher education background. Xiao Liu was from Hubei province in the middle of China where the local vernaculars are linguistically labelled 'Southwestern Mandarin'; he received his first degree in Beijing. Xiao Liu's Putonghua was near-native, with a slight trace of accent; his brother however, could only communicate in his local vernacular. The restricted command of Putonghua constrained his geographic as well as social mobility, and projected a stigmatised identity of being rural and poorly educated. As such, ideologies of homogeneity and uniformity overlay the societal diversity that characterise every real social environment (Silverstein 1996, 1998).

The growing pace of population movements such as described in extract 1 gives rise to an increase in linguistic exchanges among various communities in China, and as a result the multilingual/multidialectal nature of the 'Chinese language' and the unequally ordered indexical meanings become increasingly prominent. The latest official figures ${ }^{1}$ indicate that the migrant population was $147,350,000$ by 2005 , which counts for some 10 percent of the nation's total population. In Beijing alone, it is estimated that the migrant population was $3,570,000$ by 2005 , which is about 20 percent of the total, and this figure is increasing by 40 percent per year ${ }^{2}$. Migrant children move into Beijing city with their parents and attend city schools where they mix with local pupils, interact and exchange indexical orders. To explore the identity construction of migrant children in the context of linguistic complexity and population

\footnotetext{
${ }^{1}$ Data source: the China National Statistics Bureau, available at http://www.stats.gov.cn/tjgb/rkpcgb/qgrkpcgb/t20060316_402310923.htm, last viewed on 24 July 2007.

${ }^{2}$ Data source: Beijing Statistics Bureau, available at http://www.cpirc.org.cn/news/rkxw_gn_detail.asp?id=6574 last viewed on 15 Aug 2007.
} 
movements, I will deploy the above-discussed notions of speech community, indexicality, and ethnolinguistic identities; these notions allow me to look beyond the established language names and categories such as 'language' and 'dialect' into the real language usage and it social meanings (Dong \& Blommaert 2007; cf. Hymes 1996). In the next section, I will present metapragmatic interviews from an ethnographic fieldwork in a public primary school in Beijing that might illustrate such a sociolinguistic analysis.

\section{3. language ideology, speech community, and identity}

\subsection{The school}

The data I draw on here is the fieldwork result of a school semester in one primary school in Beijing. Data collected comprises ef non-participant observation, group and individual interviews, and audio recording of interviews and in the classroom. The school, School $\mathrm{A}^{3}$, is located in a narrow and old lane of central Beijing; the area used to be inhabited by local people, but gradually many of them have moved to newly built complexes on the outskirts of Beijing because the property price in the central Beijing keeps rising and the old single storey houses are uncomfortable and inconvenient (usually without private bathroom, toilet or running water). The area is now largely occupied by urban low-income households who originally lived here, and migrant families that rent rooms from those who move out. Migrant families rent rooms/flats in the area often because they do low skilled jobs and/or offer service to the neighbourhood, working as cleaners hired by the neighbourhood committee (juweihui), or fruit and vegetable sellers in the nearby markets. The rental may cost less on the outskirts of the city, but the transport costs are considerable, and many of their jobs require an early starting hour (for the vegetable sellers the day begins at around two in the morning). The children of migrant families that rent rooms/flats in the neighbourhood are therefore admitted into School A, which is subsidised and managed by the district educational authority. There are around 200 pupils in the school, of which half are migrant children. They were mostly born and raised in Beijing, although without Beijing hukou ${ }^{4}$. In school the migrant pupils almost always use Putonghua and sometimes even with Beijing local accent. All teachers are local.

\subsection{Monoglot ideology and ethnolinguistic identity}

As discussed above, ideologies of homogeneity and uniformity overlay the societal diversity that

\footnotetext{
${ }^{3}$ The school name and all informants' names are kept anonymous.

${ }^{4} \mathrm{Hukou}$, or household registration, groups people into agricultural/rural or non-agricultural/urban hukou-holders at birth, and transgenerationally, as children depend on their parents' hukou status. Possessing a local hukou means one is entitled to local resources and social services.
} 
characterise every real social environment. Often such ideologies - monoglot ideologies (Silverstein 1996) - are dominant in the public and institutional discourses, and school is dominated by and at the same time reproduces such ideologies. To understand the work of such ideologies, let us examine data from fieldwork observation noted down on June 14 2007. The episode runs as follows.

The setting was a drawing class; the pupils were asked to draw their friends in groups of three or four. I joined one of the groups and a pupil of that group drew me, but another one commented that what she drew didn't look like me because of the hair style - it was the hair style of countryside girls and mine was not. The girl who drew me was not pleased with this comment, and said 'So what? We are all from the countryside. Aren't you a rural girl too? Don't forget you came from the same place as me.' I felt the debate heating, interrupted them and asked 'is there any difference, countryside and city?' in an attempt to ease the tension, and the pupil who drew me replied 'isn't it enough that we are all Chinese ${ }^{5}$ ? See we all speak Putonghua.' Then we changed the topic and commented on drawings [Fieldnotes 2007-06-14].

The pupil who drew me was one of the migrant pupils, and the other pupil who commented on the hair style came from the same province. They were both about ten years old. It was amazing to see a ten-year-old being offended by identity comments and articulating a clear discourse on language and identities. There were several layers of identities displayed in the account. First, the girl who commented on the drawing distinguished me from the rural population and ascribed me an urban identity. Here the ways people dress, move, and talk collectively served as identity markers. The comment was made in a friendly and innocent way, but it triggered the dialogical practice of establishing group and individual identities. The pupil who drew me reacted with a series of provocative questions with no need to answer. This can be seen as the second phase of the identity discourse: her questions pointed to an awareness of the rural-urban divide - that the pupil who drew as well as the pupil who commented were from an 'other' place, a rural area that ranked low in relation to Beijing, whereas I, the fieldworker, am someone from 'here'. From talk with their teacher, I learned that the school and teachers were actively promoting an egalitarian idea that there was no difference between the migrant and the local, in order to protect the migrant children from being alienated or discriminated against. Therefore, the

\footnotetext{
${ }^{5}$ She emphasised on the words 'Chinese' and 'Putonghua' with a noticeable effort in her voice, as the fieldnotes 2007-06-14 shows.
} 
teacher concluded, the students had no knowledge on who were urban and who were not. However, the rural-urban divide is a social construct and school (pupils as well as teachers) in no way functions in a social vacuum. From this episode, it was clear that the pupils as young as ten years old had a good understanding of their identity categorisations to be firstly of rural origins and secondly, rural people relocated to cities - migrant identities, all of which were likely to be stigmatised.

The pupil's final comment was most informative. Recall what she said 'isn't it enough that we are all Chinese? See we all speak Putonghua.' Although she was aware of her (and the other pupil's) special identities, she blurred the rural and urban identities and overlaid them with a national identity - being Chinese people. This identity is bespoken through the language Putonghua, what Hymes calls a 'one language-one culture' assumption which argues that 'the ethnographic world can be divided into "ethnolinguistic" units, each associating a language with a culture' (1968:25). Here Putonghua is assumed to be the medium of the 'Chinese culture' which is seen as a homogeneous whole, and through this language people acquire the membership of the community - the ethnolinguistic identity.

The monoglot ideology is indeed prevailing, and the unquestioned status of Putonghua is at the centre of this ideology. Once I noted down conversations between a couple in the tube:

\section{Extract 2}

Woman: isn't Putonghua better than dialects? People from everywhere, the north or the south, all understand Putonghua; but I don't understand even a word when you speak your dialect.

Man: it is not because Putonghua is better, but because we learnt Putonghua when (we) went to school; you didn't, you grew up with it.

(Note: The woman had a Beijing accent and the man a slight southern accent. They were both in their early twenties). [Fieldnotes 2006-11-17]

It is clear here that Putonghua, although once a regional variety, is accepted as a neutral and inherently 'better' (superior) form within this monoglot language ideology; it is no long one of the varieties, it has been enregistered as a supra-local linguistic repertoire (Agha 2003). The enregistration of Putonghua deserves a separate paper; here I focus on the imagined homogeneity it has through the monoglot ideology and the image of singular ethnolinguistic identities it projects. In the above described school observation, the migrant pupil who drew me claimed that Putonghua unifies people who (believe they) speak it and this belonging to a language community results in uniform and stable ethnolinguistic identities. However, is the 
ethnolinguistic identity so waterproof that none of the actual linguistic diversity and social complexity filters through to the linguistic field of education? The next section will present metapragmatic talks by local pupils and teachers on the linguistic features of migrant pupils and demonstrate how linguistic features become emblematic of individual and group identities, and how such identities can affect the evaluation of migrant pupils' performance at school.

\subsection{Metapragmatic talk}

Metapragmatic talk - talk by pupils and teachers on how migrants talk, makes indexical statements explicit, and links migrant pupils' linguistic features (e.g. accents) to identity categories. By describing their perceptions about and evaluation of migrants' language, pupils and teachers exercise an 'othering' process, in which 'we' produce and share similar indexical values, whereas 'they' (the migrants) don't. Therefore the 'migrant' identities are ascribed to them by others and leave marks on migrant pupils' performance appraisal as well as life opportunities.

\section{Extract 3}

Interview with Jun, a local boy, during class break on 12 June 2007 [Field Recording 2007-0612-V049]. JD refers to me, the fieldworker; Xing is Jun's migrant classmate. [Abbreviated transcription] ${ }^{6}$

$1 \quad$ JD: Do you share a table with Xing?

Jun: Yeah.

JD: How is her Chinese, her pronunciation?

Jun: Pronunciation, very bad.

5 JD: Does she pronounce unclear?

Jun, Yeah, we say 'cuo', she says 'chuo'.

JD: Does she have an accent?

Jun: She is a migrant child.

JD: so that she is not very clear (in pronouncing words)?

10 Jun: I am from here.

JD: I know you are from here \{with a smiling voice . But, do you think, that accent

\footnotetext{
${ }^{6}$ Transcription conventions:

Words in bold refer to speakers' emphases.

'. ' segment weaker than the rest of the sentence.

' \{\} ' transcriber's comments

'( )' omitted part in the utterance
} 
influences her performance in Chinese lessons?

Jun: Yeah. People from other places (provinces) are always unclear.

JD: Do you help her correct her pronunciation?

15 Jun: Yeah I do correct her, but she just can't make it right! She (is) a migrant and can't get it right.

JD: Do you feel any difference between her and us?

Jun: I feel they migrants speak differently; many times I can't figure out what she has to say.

20 JD: difficult to communicate?

Jun: Yeah. Once I sat there and doing something she came to me and said to me "XXXXXXX" \{unintelligible talk\}

JD: $\{$ laughing voice $\}$ but you can't understand...

Jun: I can't! She was very $\bullet$ silly $\bullet\{$ low voice as if to tell me a secret $\}$.

Let us take a close look at what happens in the transcript. The interview was taken during class break after several weeks' non-participant observation in the class. There were 21 pupils, 12 girls and 9 boys, 5 local and 16 migrants. Most of them were eight years old; the classroom was organised in rows, with two pupils sitting next to each other so that they could work in pairs. There was a blackboard at the front of the classroom and teachers stood between the blackboard and the pupils. Jun was a local boy who sat next to Xing. They had a lot of interaction in and out of class. However, it is the quality, not the frequency, of interaction that matters: the section immediately prior to the interview was a Chinese class ( $y u$ wen), and Xing stood up and answered a question from the teacher with incorrect pronunciation. Almost everyone in the class shouted to correct her, and Jun was the loudest. They shouted because they had all volunteered to answer the question: Xing got the chance to do so but she did not make good use of the opportunity. Xing was embarrassed and her facial expressions indicated a clear sense of inadequacy.

This episode triggered my interview with Jun. Jun was a very vocal boy speaking with a marked Beijing accent. I started the interview with a few casual questions and then asked him to comment on Xing's language. In line 4 he assessed Xing's pronunciation to be 'very bad', and emphasised 'very'. The utterance in heavy Beijing accent and with the particular emphasis meant something more than 'very bad'; it was 'couldn't be worse', hopeless. Then I pushed him for more details and he gave an example that what he pronounced as 'cuo' ([ts'o4], meaning 'wrong'), Xing would pronounce as 'chuo' ([ch'ro4], meaning 'more'). Many dialects do not 
distinguish the dental sibilants $(z, c, s)$ from the retroflexes $(z h i, c h, s h)$, and as Robert Ramsey demonstrates, the distinction is a mark of standard Putonghua and the mastery of such subtle differences is much admired by people living outside of the capital; they are often unable to pronounce these sounds in the right way and most do not even try to imitate the 'correct' forms. In practice people get along without the distinctions (Ramsey 1987:43-44).

However, the small linguistic feature indexes big identity issues. Immediately after his description of how Xing talked, Jun pointed out that Xing 'is a migrant child'. This didn't answer my question 'Does she have an accent?' Instead of commenting on her language, Jun stuck an identity label of 'migrant identity' on Xing, linking her accent directly with identity. This direct link between accent and migrant identity is a classic example of indexicality, in which an accent points to an identity. I kept on asking about her way of talking: 'so that she is not very clear (in pronouncing words)', but once again Jun put the enquiry on linguistic aspects aside and focused on identity 'I am from here' in line 10. This comment is interesting in several ways. First, Jun dodged my question for the second time, which indicated that the idea that Xing was a migrant was strong enough to make him ignore the questions of a class observer who was as powerful as his teacher. Second, there were jumps in his answers: in line 8 what he said was actually 'She is a migrant child, and therefore she speaks with an accent', and in line 10 he was saying 'I am from here, and my way of speaking is the right way, so that I am in a position to judge her accent'. In this sense, Jun answered my questions by relating linguistic features with identities again, and the identities were not equal - Jun was a local boy and therefore had the access to the prestige resource of the Beijing accent (Beijing accent is not exactly Putonghua but many people, local and non-local alike, confuse the two). Xing's identity was ranked lower because the semiotic resources she had access to and deployed were stigmatising. Therefore identities are organised unequally in relation to access to the identity-building resources and as the semiotic resources are stratified, so are the identities. Third, Jun was exercising an othering process, in which Xing was grouped by Jun as 'migrants', one of the others, because her accent betrayed her as belonging to a different community, whereas Jun and I were $u s$ who shared similar indexical values.

The othering process continued to line 13 'People from other places ${ }^{7}$ are always unclear'. Here everyone who was not a local Beijing person was grouped as others. Compared to the nation, Beijing is a tiny place; the enormous diversity of the nation was overlaid by the idea that all others spoke in the same way which was 'always unclear'. The Beijing 'native

\footnotetext{
${ }^{7}$ wai di ren, literally 'other place people', refers to anyone who comes from places other than a speaker's locality within the country.
} 
speaker' generalised his perception of one migrant pupil's linguistic features to all 'non-Beijing' people and artificially distinguished 'Beijing speakers' and 'non-Beijing speakers' as two language communities, whether or not the latter group share same indexical complexes. In line 15 Jun assumed the right to assess Xing's language again and indicated that it was difficult to 'correct' her and this again evoked the indexical orders - she enters a space where 'central' accent dominates, i.e. Putonghua; her communicative ability was misrecognised (in the sense of Bourdieu 1990), and she had to adjust and adapt to the rules of the dominant. The dominant ones, in contrast, have no obligation to reciprocate this accommodating move.

Next, I made Jun describe the linguistic differences he perceived between 'her' and 'us'; once again he responded in a generalising way - 'the migrants speak differently...I can't figure out what she has to say' in line 18 and 19. By referring to 'the migrants' he was no longer commenting on one person's language, but on a whole community that he found unable to communicate, and who were therefore disqualified as 'language- less' ${ }^{8}$. In line 21 and 22 Jun imitated Xing's language by unintelligible talk which echoed his 'language- less' comment - it was bubbling rather than language. If she spoke like that, what sort of person did that make her? 'She was very ${ }^{\bullet}$ silly $^{\bullet}$ ' in line 24 . Xing's accent, a probably comfortable marker of in-group identity in her home area became a symbol of rural, unsophisticated, unintelligent identity in Beijing. It is an 'abnormal' accent, bespeaking an 'abnormal' identity. Jun lowered the voice and pronounced 'silly' in a secretive style, to stress that he shared the secret with me because we were both 'us'. Throughout the transcript, we see how Xing's language was evaluated and disqualified, and how she was 'grouped' into a community of 'non-Beijing speakers' which therefore ascribed a migrant identity to her on the basis of her local peer group criteria through a metapragmatic discourse on her language.

\subsection{Teacher's evaluation}

Having examined how pupils perceived the language and identity of their migrant peers, let us look at a teacher's evaluations on her migrant pupil's identity and linguistic forms, which have an impact on the performance appraisals. Teachers are the powerful party in teacher-pupil relations, whose appraisals of the pupils' performance are often crucial for pupils' academic career as well as their future development. The following extracts are taken from a feedback interview with Miss Zhang, a Chinese language ( $y u$ wen) teacher and a native of Beijing, on a questionnaire about her students' language and performance distributed to her and her

\footnotetext{
${ }^{8}$ Similar examples can be found in Blommaert et al. 2005a that a Bulgarian immigrant woman who was labelled as 'speaking no language' by local mainly Dutch-speaking researchers.
} 
colleagues at the beginning of the fieldwork. In the feedback interview she was invited to elaborate the comments she made and to give examples where necessary.

\section{Extract 4}

Interview with Miss Zhang in the staff office on 21 June 2007 [Field recording 2007-06-21V044]. Hong was a pupil of Miss Zhang.

1 JD: Oh so Hong is a migrant child; but once I chatted with her and she said she was local, so I had the idea that she is a local...

Miss Zhang: They, well, they, they have all grown up in Beijing and they think they are Beijing people, but actually they are not. They are grade 1 (aged 7-8) and have no idea

5 who they are; they think they live in Beijing and they are therefore Beijing people but they are not.

I went through the questionnaire with Miss Zhang and was surprised that she marked Hong as a migrant child. A few days prior to the interview Hong and I had a talk in which she said that she was a local child and she even went to a local kindergarten (which is often unaffordable to many migrant families) before attending this school. I had no doubt about what she told me as she spoke with a nearly perfect Beijing accent. But here her self-ascribed local identity was denied and she was ascribed a 'migrant identity' although she grew up in Beijing and acquired a local accent. In line 3 Miss Zhang emphasised 'they', in the same way that Jun did in extract 3, and extended her comment to the migrant population as a homogeneous community. Being a local person and a teacher, Miss Zhang was in the position to judge Hong's identity and to decide that she was not a local although she herself thought she was. On Hong's language and performance, Miss Zhang's evaluation was:

Extract 5 [Fieldwork recording 2007-06-21-V045]

$1 \quad$ JD: ...then does she have an accent? Miss Zhang: She doesn't distinguish ' $n$ ' and ' $l$ '. People from Sichuan all speak like this. ..... \{another teacher interrupted and told a story about her experiences in Sichuan\}

5 JD: $\{$ pointing to the questionnaire well, here, 'her accent has a big impact on her performance', did you mean the ' $n$ ' and ' $l$ ' distinction? 
Miss Zhang: Yes. Her Pinyin', you see, the tasks 'read Pinyin and write down words', she has never done it well.

JD: = in Chinese lessons...

10 Miss Zhang: = she has difficulties in Pinyin.

JD: but her overall remarks are average (pointing to the questionnaire item where Miss Zhang selected the middle one out of a five-point Likert scale) ...

Miss Zhang: yes average.

JD: so you meant her overall performance?

15 Miss Zhang: because pronunciation is only one aspect that influences her study; but things such as her intelligence, her cognitive ability, are quite good which make up for it. JD: otherwise she could do better (in the evaluation)...

Miss Zhang: exactly.

Having noted Miss Zhang's comments on Hong's identity in extract 4, I interviewed her about Hong's language. The linguistic feature of Hong was the confusion of dental nasal $[n]$ and dental lateral [ I ]. It was uncertain to me whether this mix-up was an influence of accent or a result of unclear pronunciation ${ }^{10}$ that particularly common among children this age even in Beijing.

However, Miss Zhang perceived Sichuan dialect speakers as a uniform community through this linguistic feature (the incapability of distinguishing [n] and [I ]) 'People from Sichuan all speak like this' in line 2 and 3. Later I asked Miss Zhang whether there were regional differences in the linguistic features among the migrant pupils in her class and she responded that she did not think there were salient differences - 'I didn't notice much difference' [Fieldwork recording 2007-06-21-V045]. Why did Miss Zhang on one hand comment that all Sichuan native speakers shared the feature of confusing [n] and [ I ], but on the other hand noticed no difference among the regional varieties? She was not self-contradictory; the information she gave reflects the language ideology that self-evidently marks Putonghua as the correct language which defines the city's boundaries: people of this city speak perfect Beijing dialect which is the original form of Putonghua, therefore Beijing people speak perfect Putonghua; all those who do not speak like 'us', Beijing people, are migrants, and 'they' have accents, no matter what kinds of accents they speak. This is what Irvine \& Gal (2000) call 'erasure': dominant ideologies making some features of reality invisible. In this teacher's eyes the overwhelming linguistic differences

\footnotetext{
${ }^{9}$ Pinyin is the Romanised alphabet system that represents Putonghua. It has been the official spelling system of Mainland China since 1958.

${ }^{10}$ What we call da she tou, in Chinese, literally 'big tongue'.
} 
between varieties are invisible, and what matters is the difference between Beijing speakers and non-Beijing speakers.

Therefore one small feature of language has become emblematic of individual and group identities, and the migrant identity has amplified the linguistic feature - it would have gone unnoticed if this particular phonetic mix happened in the speech of a Beijing child, but here Hong was labelled as a migrant child and thus 'her accent has a big impact on her performance' in line 5. It was marked ' 4 ' on the five-point Likert scale. This option was next to the extreme end of the scale 'very big impact' (the five points are: no impact, a little impact, some impact, big impact, very big impact), and therefore Miss Zhang's questionnaire answer to this item indicated that the 'impact' was considerable. However, her interview elaboration on the answer showed that the 'big impact' was actually limited to Hong's Chinese, unaffected her other subjects; it was limited to the Pinyin ${ }^{11}$ aspect of her Chinese, unaffected other aspects such as writing and grammar. The task 'read Pinyin and write down words' requires pupils to decode Pinyin and to give the character form of the word. For example, he 2 liu2, the Chinese character is “河流', meaning river. If a pupil doesn't distinguish [n] and [ I ], the second character liu2 will become niu2, which means 'ox'. Children who confuse the consonants can make mistakes in this kind of task, but a morpheme (such as ' $h e 2$ ' or 'liu2') rarely stands on its own; rather a word often consists of two or more morphemes. Therefore, one still has a chance to get the word right because of the cue from the other morphemes in the word. Nevertheless, a migrant pupil can have lower than average performance in this kind of task which specifically tests their mastery of the 'standard' pronunciation; however, this should not have a 'big impact' on a pupil's performance, as the teacher indicated in the questionnaire.

From line 11 to line 18 Miss Zhang commented on Hong's general performance and pointed out that Hong was intelligent and cognitively able to achieve good learning results. If she spoke 'better language' she could have received a better general appraisal from the school. It is clear now how the linguistic features of a migrant child influence the appraisal she receives: the migrant child is different because she speaks differently; the differences index identities of being rural, working class, and migrant. Within the monoglot language ideology, all these indexicalities are not made explicit; it simply takes the form of being 'incorrect'. Her language is 'incorrect'; she should have make efforts to acquire the 'correct' language, and if not, she is not working hard enough. Therefore her performance is negatively influenced by the 'incorrect' language given the 'fact' that she is not able to adjust to the 'correct' form. The evaluation of

\footnotetext{
${ }^{11}$ Pupils are instructed to represent Chinese characters with the Romanised alphabet that is known as Pinyin in their early stage of Chinese learning; see also footnote 9.
} 
Hong's performance was done in a seemingly neutral way, with recognition of her cognitive ability, and indeed in many occasions I observed support and encouragements from both local teachers and pupils towards migrant children; but this case demonstrates that Hong's language played a role in the appraisal and as her teacher pointed out, she could be a 'better' student if she spoke the 'correct' language. In this way, school institutionally supports the language ideology with Putonghua at the centre and at the same time reproduces the dominant social values and hierarchies.

\section{Conclusion}

What I have shown in this paper is the construction of migrant identities through the metapragmatic discourses of migrant pupils, their local peers, and teachers in the context of linguistic complexity and population movement in China. Despite the remarkable sociolinguistic diversity, ideologies of homogeneity and uniformity penetrate public discourses as well as institutional discourses such as in schools. The monoglot language ideology in China often revolves around Putonghua - an association that feeds into the 'one language-one culture' assumption and results in an imagined singular, clear and stable ethnolinguistic identity. In the actual linguistic exchanges, however, the one-to-one relationship is blurred when we observe that multiple 'languages', 'dialects' or 'accents' are deployed as a linguistic repertoire of migrants, that various speech communities share one 'language', and such communities are defined in relation to the sharedness of indexical values. The concepts of speech community, ethnolinguistic identity and indexicality allow me to look beyond established categories such as 'language' and 'dialect' into the real linguistic occurrences and their effect on school pupils' individual and group identities. The three examples presented in the paper demonstrate the application of such a linguistic anthropological approach in an attempt to address the real social impact of linguistic diversity.

In the first example I observed a drawing class at the Beijing primary school during which a migrant pupil articulated a metapragmatic discourse on her own and her fellow-pupil's identities. It was clear that she was aware of her rural origin and possibly aware of the negative image such an identity projects. However, she overlaid this migrant identity with a national identity by 'isn't it enough that we are all Chinese? See we all speak Putonghua', and this utterance pointed to a stable identity category through the claimed belonging to a homogeneous language community. Notice that it was perceived as natural, by a migrant pupil, rather than a dominant one such as a local pupil or teacher in the social space. The move towards a homogeneous 'national' identity layer is, as Bourdieu (1987) argues, an example of the social 
structures internalised in people. Thus 'even the most disadvantaged, tend to perceive the world as natural and to find it much more acceptable than one might imagine' (Bourdieu 1987:520).

The "taken-for-granted" disposition takes the shape of an orientation towards Putonghua in this first example, and this is echoed in the second and the third examples, both of which are metapragmatic discourses on migrant pupils' language and identities. Meanwhile, the blur of migrant and local identities in the first example was also challenged in the second and the third examples. The second example showed the comments of a local Beijing pupil on his migrant fellow-pupil's accent: the accent indexed and was emblematic of her identities of being of rural origin, a migrant to the city, unsophisticated and less intelligent. The third example examined a teacher's comments on her pupil's identity, language, and performance. Here we saw small features of language again becoming markers of individual and group identities, and such identities have an impact on the appraisal of migrant pupils' performance at school.

In spite of the dominance of in a largely egalitarian ideology of China, where the informants of the three examples do not acknowledge the social distance between the migrant and the local in the school, the migrant pupil's self-claimed identity in the first example is denied by the local pupil and the local teacher. The observations in this paper lead us to study the population movement at the macro level from a perspective of 'small' linguistic features and individual identity at a micro level, and to gain an insight into the social structure that is produced and reproduced through practices such as interactions at school.

\section{References:}

Agha, Asif 2003. The social life of a cultural value. Language \& Communication 23:231-273.

Blommaert, Jan 2005. Discourse: A Critical Introduction. Cambridge University Press: Cambridge.

Blommaert, Jan 2006. Language Ideology. In Keith Brown (ed.) Encyclopaedia of Language and Linguistics $2^{\text {nd }}$ Edition. Oxford: Elsevier. Volume 6:510-522.

Blommaert, Jan \& Jef Verschueren 1998. Debating Diversity. London: Routledge.

Blommaert, Jan, James Collins and Stef Slembrouck 2005. Spaces of multilingualism. Language and Communication 25:197-216.

Blommaert, Jan, Lies Creve \& Evita Willaert 2006. On being declared illiterate: languageideological disqualification in Dutch classes for immigrants in Belgium. Language \& Communication 26: 34-54.

Bloomfield L. 1933. Language. New York: Holt, Rinehart and Winston.

Bourdieu, Pierre 1990. The Logic of Practice. Cambridge: Polity Press

Bourdieu, Pierre 1987. In other words. In Revel, Jacques and Lynn Hunt 1995. (eds) Histories. French Constructions of the Past 514-520. New York: The New York Press.

Dong, Jie K. and Jan Blommaert 2007. Space, scale and accents: constructing migrant identity in Beijing. Working paper 44 in Urban Language \& Literacies. 
Gumperz, John 1968. The speech community. International Encyclopaedia of the Social Sciences: 381-386. London: MacMillan.

Gumperz, John and Dell Hymes (eds) 1972. Direction in Sociolinguistics: The Ethnography of Communication. London: Blackwell.

Gumperz, John 2003. Response essay. In S. Eerdmans, C. Prevignano, and P. Thibault (eds) Language and Interaction Discussions with John J. Gumperz 105-123. Amsterdam: John Benjamins Publishing.

Hymes, Dell 1968. linguistic problems in defining the concept of 'tribe'. In Helm, J. (eds) Essays on the Problem of Tribe 23-48. Seattle: American Ethnological Society and University of Washington Press.

Hymes, Dell 1996. Ethnography, Linguistics, Narrative Inequality: Towards an Understanding of Voice. London: Taylor and Francis.

Irvine, J. and G. Gal 2000. Language ideology and linguistic differentiation. In Kroskrity P. (eds) Regimes of Language: Ideologies, Polities, and Identities 35-83. Santa Fe: School of American Research Press.

Rampton, Ben 1998. Speech community. In Verschueren, J. Ostman, J.-O., Blommaert, J. and Bulcaen, C. (eds) Handbook of Pragmatics 1-30. Amsterdam: John Benjamins.

Ramsey, Robert 1987. The Languages of China. Princeton University Press: New Jersey.

Silverstein, Michael 1996. Monoglot standard in America: Standardization and metaphors of linguistic hegemony. In D. Brenneis \& R. Macaulay (eds) The Matrix of Language: 284306. Boulder: Westview.

Silverstein, Michael 1998. Contemporary transformations in local linguistic communities. Annual Review of Anthropology 27: 401-426.

Saussure, F de 1996. Course in general linguistics. In C. Bally \& A. Sechehaye (eds) W. Baskin (trans). New York: McGraw-Hill. 